Kristina Vištica

UDC: 821.111(73).09:004.738.5

Alfa univerzitet, Beograd

DOI: 10.18485/dh.2015.2.ch24

\title{
DIGITALNA HUMANISTIKA PROTIV RASIZMA - ULOGA BLOGA U ROMANU AMERIKANA
}

\begin{abstract}
Sažetak
Uz brojne definicije, digitalna humanistika bi se mogla definisati i kao uticaj digitalnog na humanističko i analiza njihovog prožimanja. Često kritikovana kao oruđe koje stvara digitalni jaz (ekonomski, klasni, rasni itd.), brojni projekti (npr. Google Books) sačuvali su od zaborava i uništenja hiljade kniga i podstakli tzv. "čitanje na daljinu", a moderne tekstualne forme (npr. Twitter, blog itd.) promenile su percepciju književnosti, ali i postale instrument otpora i reformi. Feministička književnica Čimamanda Ngozi Adiči oblikuje strukturu svog romana Amerikana kroz delove tekstova koji piše junakinja romana Ifemelu. Ovi odlomci iz blogova sumiraju teme koje se tiču rasizma u Americi, a kroz lično iskustvo Nigerijke - Ifemelu, Adičijeva daje primere kako se pitanja rasizma provlače kroz svakodnevni život. Koristeći ovu modernu, digitalnu formu unutar klasične forme romana, Adičijeva pokazuje spoj tradicionalnog i modernog, neraskidiv u današnje vreme. Stoga, analizirajući roman Amerikana cilj ovog rada je da se utvrdi uloga digitalne forme - bloga na klasičnu strukturu romana, kao i uloga bloga u podizanju svesti i borbi protiv rasnih problema u Americi.
\end{abstract}

Ključne reči: Amerikana, blog, digitalno, rasizam, tradicionalno.

Kompleksnost digitalne humanistike se, pre svega, ogleda u nemogućnosti iznalaženja jedne sveoubuhvatne definicije ovog pojma. Prosto rečeno, to je uticaj digitalnog na humanističko, i obrnuto, kao i istraživanje tog međusobnog uticaja. Knjiga Rasprave o digitalnoj humanistici daje preko dvadeset definicija, dok je taj broj na internetu (Kako vi definišete digitalnu humanistiku?) mnogostruko veći. ${ }^{1}$ Za potrebe ovog rada koristiće se definicija Centra za digitalnu humanistiku Univerziteta Kalifornija: “Di-

1 ideti na: http://www.artsrn.ualberta.ca/taporwiki/index.php/How_do_you_define_Humanities_Computing_/_Digital_Humanities\%3F 
gitalna humanistika interpretira kulturni i društveni uticaj novih medija i informacionih tehnologija, a takođe i stvara i primenjuje ove tehnologije kako bi mogla da ispituje kulturna, društvena, istorijska i jezička pitanja". ${ }^{2}$

Razvoj digitalne humanistike je uticao i na naučnike i na način na koji se sprovode naučna istraživanja. Stvaranjem novih, hibridnih formi tekstova, menja se i pristup informacijama: "Format više nije ograničen štampanom knjigom. Teorijski gotovo ne postoji granica u veličini i linkovi hiperteksta pružaju koristan način korišćenja anotacija itd. [...] Može biti trenutno dostupan javnosti i lako se može menjati i ažurirati" (Hoki, 2008:31). Peri Vilet dalje naglašava da: "Elektronski tekstovi daju humanističarima pristup radovima koji su se ranije teško nalazili" (Vilet, 2008:286), a sami tekstovi u elektronskom formatu daju svojevrsni, sveobuhvatni "isprepletani" tekst. Takođe, digitalna humanistika "otključava ogromni interpretativni potencijal u istraživanju novih načina da ljudi daju smisao njihovim društvenim svetovima" (Evans i Ris, 2012:29). Oni navode da iako je nesumnjiva uloga novih medija u digitalnoj humanistici tj. u životu pojedinca oni "ne prenose jednostavno poruke, oni utiču na našu vezu sa svetom" (Evans i Ris, 2012:22).

Mnogobrojni projekti proteklih godina (npr. Gutenberg, Google Books i sl.) pokrenuti su sa svrhom očuvanja i dostupnosti starih, teško dostupnih izdanja knjiga. Pored očuvanja već postojećih dela, novi digitalni mediji su iznedrili i brojne nove elekronske forme koje redefinišu klasičnu književnost i ustaljene norme pisanja. Društvene mreže (Fejsbuk, Tviter i dr.) preoblikuju klasične forme teksta, jer u povezivanju i komentarima pripadnici ovih grupa sami formiraju nove tekstove:

Tviter, zajedno sa blogom i drugim onlajn načinima za izražavanje, je ispisao digitalnu humanistiku kao mrežnu topologiju, tj. linije koje povlače skupovi afiniteta, koji se formalno i funkcionalno manifestuju u tome ko koga prati, ko se sa kim sprijateljuje, ko kome tvituje i ko šta lajkuje. (Kiršenbaum, 2012:8).

Blog, kao nova tekstualna forma, prevazišao je svoju prvobitnu namenu (onlajn dnevnik) i postao snažno oruđe u popularizaciji stavova 
pojedinaca i isticanju društvenih, političkih i ekonomskih pitanja. Trevor Ovens smatra blog "kulturnim fenomenom":

Kao žanr javnog pisanja, iz njega proističe skup normi i pravila koji bi trebalo da naučimo njegovim korišćenjem. Ukratko, pisanje bloga je zapravo skup veština koje vredi negovati. Kada počnemo da mislimo o tehnologiji pisanja bloga u ovom svetlu, on postaje nešto što umesto da dopunjuje instrukciju, ruši i transformiše obrazovanje. (Ovens, 2012:411).

Najnoviji roman Čimamande Ngozi Adiči, Amerikana (2013), kao integralni deo teksta ima odlomke bloga koji piše junakinja romana - Ifemelu. Ukratko, roman je priča o ljubavi i rasi koja okružuje mladi par iz Nigerije, Ifemelu i Obinze. Ifemelu uspeva da pobegne iz diktatorske Nigerije u Ameriku, ali nakon 9.11. za Obinzea je nemoguće da je prati, te on ilegalno odlazi u Britaniju i tamo pokušava da stvori novi život. Godinama kasnije, Obinze je bogati poslovni čovek u novoj, demokratskoj Nigeriji, a Ifemelu uspešna i uticajna blogerka iz Amerike. Adičijeva romanu daje svojevrsni srećni završetak (po prvi put u njenom književnom opusu), ujedinjujući Ifemelu i Obinze u njihovoj ljubavi prema Nigeriji i jedno prema drugome.

Serena Gvarancino navodi da za Adičijevu razlog za preobraćanje junakinje romana u blogerku leži u želji da roman bude društvena kritika i to na način drugačiji od onog koji se očekuje u književnoj fikciji (Gvarancino, 2014:2). Adičijeva koristi blog kao kanal za iznošenje gorućih pitanja u Americi verovatno zato što je svesna uloge elektronskih medija i njihovih hibridnih tekstualnih formi u svakodnevnom životu. Sama autorka je veoma prisutna u sajber prostoru, može se reći da je "viralna". Jednostavna pretraga imena Čimamande Ngozi Adiči na Guglu daje preko pola miliona rezultata, a na kanalu Jutjub postoji preko četrdeset hiljada rezultata. ${ }^{33}$ Takođe, Adičijeva ima i svoju stranicu na društvenoj mreži Fejsbuk koju vodi i uređuje njen izdavač Alfred Knopf.

Kako su digitalni mediji neodvojivi od popularne kulture današnjice, Adičijeva svoju popularnost duguje i pop muzici. Naime, pop diva Bijonse 
je iskoristila (na obostranu korist) deo govora Čimamande Ngozi Adiči "Svi bi trebalo da budemo feministi" u tekstu pesme ***Besprekorna (eng. ***Flawless). ${ }^{4} \mathrm{Na}$ taj način Adičijeva je doprla do mnogobrojne publike koja inače ne pripada akademskim krugovima i verovatno ne bi drugačije bila u kontaktu sa ovim feminističkim stavovima. ${ }^{5}$

U jednom od intervjua Adičijeva je rekla da je u Americi otkrila da je crna, i da biti crn u Americi ima značenje. ${ }^{6}$ Odgovarajući na komentare o rasizmu u Nigeriji, Adičijeva naglašava da je njena namera bila da se iznesu društveni problemi u Americi, što zauzvrat ne znači da tih problema nema u Nigeriji. Autorka je često naglašavala opasnost "jedne priče", u ovom slučaju priče koja izjednačava sve Afrikance i koja ih predstavlja jedino u negativnom svetlu: "Jedna priča stvara stereotipove, a problem sa stereotipovima nije da su oni netačni, već nekompletni. Oni čine da jedna priča postane jedina priča" (Adiči, 2009). ${ }^{7}$ Stoga, Adičijeva putem bloga pokušava da prenese različite, drugačije priče, jer: "Priče se koriste za obespravljanje i klevetanje, ali priče se takođe mogu koristiti za osnaživanje i humanizovanje" (Adiči, 2009). ${ }^{8}$

$4 \quad$ "Učimo devojčice da se skupe, da se umanje Kažemo devojčicama, "Možete biti ambiciozne, ali ne previše, Možete težiti da budete uspešne, ali ne previše, U suprotnom, ugrozićete muškarca."

Zato što sam ja žensko od mene se očekuje da težim braku Od mene se očekuje da donosim životne odluke Ne zaboravljajući da je brak najvažniji. Brak može biti izvor radosti i ljubavi i uzajamne podrške, Ali zašto učimo devojčice da teže braku a ne učimo to isto dečake? Vaspitavamo devojčice da jedna u drugoj vide konkurenciju, Ne zbog posla ili dostignuća, što smatram da je dobra stvar, Već zbog pažnje muškaraca.

Učimo devojčice da ne mogu da budu seksualna bića na onaj način na koji su to dečaci. Feminist: osoba koja veruje u društvenu, političku i ekonomsku jednakost polova." Više na: http://www.azlyrics.com/lyrics/beyonceknowles/flawless.html

$5 \quad$ Na dan 04.08.2015. pesma ***Flawless je na You Tube kanalu imala 13, 698, 179 pregleda.

6 Više na: https://www.youtube.com/watch?v=2ijEqposkyk

7 Više na: http://www.ted.com/talks/chimamanda_adichie_the_danger_of_a_single_story/ transcript?language $=e n$

8 Id. 
U romanu Amerikana digitalno se pojavljuje u dva oblika: digitalne forme i mediji koje koriste junaci romana za komunikaciju i Ifemelin blog koji ispituje pitanja rase, klase i roda u Americi. Kao neodvojivi deo popularne kulture, digitalni mediji su integralni deo života u Americi, Britaniji i Nigeriji. Pristup informacionim tehnologijama je, nažalost, uslovljen ekonomskim klasnim raslojavanjem. Pristup digitalnom oslikava društveni i ekonomski status (mnogo toga je "trulo" u državi Nigeriji, ali je važno posedovati Blekberi, otvoriti nalog na Fejsbuku i hvaliti se svojim imovnim stanjem itd.): "Sad je i frizerka što joj upliće kosu imala mobilni telefon, i prodavac prženih banana što stoji kod pocrnelog roštilja takođe ima mobilni telefon" (Adiči, 2014:451). Adičijeva navodi da je Nigerija, između ostalog, poznata i po svojim 419 internet prevarama. Međutim, digitalne novotarije spajaju Ifemelu i Obinze, a Obinze (kao što Ifemelu koristi svoj blog) koristi imejl kako bi pisao svojevrsni dnevnik o svom ilegalnom životu u Britaniji: "Pišući njoj, pisao je samome sebi" (Adiči, 2014, 438439). Oboje, i Ifemelu i Obinze, kroz svoje priče pokušavaju da spoje svoja dva identiteta: nigerijski i migrantski. Došavši iz države u kojoj su pripadal srednjoj klasi, u Americi i Britaniji oni su migranti, i to crni, koji su nevidljivi za društveni sistem:

Onoga dana kada je dobila prvi džank imejl, rekla je Dikeu: "Pogodi šta je bilo? Danas sam dobila pismo." Ta ponuda za kreditnu karticu, s njenim imenom ispravno napisanim elegantnim kosim slovima, obodrilal ju je jer se osećala malo manje nevidljivom, malo prisutnijom. Neko je znao za nju. (Adiči, 2014:159)

Ono što je isprva samo Ifemelin imejl prijateljici Vambui prerasta u njen blog: Rejstint ili Razna zapažanja neameričke crnkinje o američkim crncima (nekada poznatim kao crnje): "To je sve sirova istina. Ovo bi trebalo da pročita više ljudi. Treba da pokreneš blog" (Adiči, 2014:352). Meri Kros popularnost bloga vidi u tome što je besplatan, pruža lakoću i spontanost samoizražavanja i ima svoju publiku (Kros, 2011:4). "Surova istina" koju Ifemelu piše je ono što čitaocima treba, a što pruža necenzurisana forma bloga. Kros navodi: "Ljudi deluju manje inhibirani onlajn, verovatno zbog toga što mogu biti anonimni ili da koriste nadimak ili lažan identitet, 
ili možda zato što niko ne može da ih vidi; drugi ljudi deluju udaljeniji u internet razmeni" (Kros, 2011:6).

lako je Adičijeva opisala Ifemelu kao samouverenu devojku sa izrazito formiranim stavovima, anonimnost koju joj pruža sajber prostor i pisanje bloga je kuraži da odvažnim jezikom istakne probleme sa kojima se susreće u Americi. Rečnik koji Ifemelu koristi je ponekad vulgaran i grub, ali ta "sirovost" zapravo najbolje opisuje ogoljenu istinu. Ifemelu često koristi stvarne scene iz svog života kao osnovu za buduće postove. Nekada su tekstovi blogova u skladu sa ostatkom priče romana (npr. nakon "pomirenja" sa afričkim kovrdžama i prihvatanja "crne lepote", sledi tekst "Zašto crnkinje tamne kože - i Amerikanke i neamerikanke - vole Baraka Obamu" (256-257) gde se pozdravlja izbor budućeg predsednika u odabiru "jedne od njih"), a nekada nije potpuno jasno kako se uklapaju u deo koji im prethodi (npr. nakon priče Dikea o losionu za sunčanje koji mu je uskraćen zato što je crnac sledi tekst "Uputstva neameričkim crncima za razumevanje Amerike: američki tribalizam" (221-222)). Kao što i u samom romanu priča ide napred-nazad, tako i blog skače sa jednog gorućeg pitanja na drugo. Okidač za pokretanje bloga za Ifemelu je pitanje rase sa kojom se susreće u Americi gde saznaje da postoji više od "50 nijansi crne" kao i bitna razlika između Afroamerikanaca i Afrikanaca - američkih i neameričkih crnaca, a u samom tekstu romana blog je metafora klasne, rasne i rodne neravnopravnosti u Americi.

Za razliku od štampanih radova, blog ne trpi uređivačku cenzuru. lako tekst predstavlja lične stavove pojedica koji ga piše, blog kao digitalni tekst nije ograničen. Blogeri svojim pisanjem utiču na svoje čitaoce da preduzmu konkretne korake po pitanju tema koje se obrađuju, ali komentari čitalaca, takođe, učestvuju u daljoj nadogradnji teksta. Čitalac je i korisnik teksta i njegov stvaralac. Međutim, autor bloga ipak može da utiče na smer u kome se novonastali tekst kreće:

Blogeri takođe mogu da brišu komentare čitalaca kako bi ih sankcionisali zbog kršenja normi ponašanja, i mogu da menjaju i brišu postove i komentare koje sami pišu. Ovo znači da oni imaju kontrolu nad prepiskom i time nad prirodom teksta u razvoju. (Bolander, 2013:41) 
Na taj način bloger može da ograniči svoje čitaoce. U romanu vidimo da Ifemelu briše negativne komentare na njene postove, ali ne zalazi u prepisku sa svojim čitaocima. Zaključujemo da ona iznosi probleme i svoja zapažanja, ali ne želi nikoga da ubeđuje: "Ne želim da objašnjavam, želim da posmatram i zapažam" (Adiči, 2014:371). Inertnost koju iskazuje Ifemelu tj. njeno odbijanje da aktivno učestvuje u rešavanju društvenih problema koje opisuje u svom blogu kritikuje njen momak Blejn, američki crnac:

"Ne zaboravi da ljudi ne čitaju tvoje tekstove da bi se zabavili, čitaju ih kao komentare ovdašnje kulture. To nosi pravu odgovornost. Klinci u koledžima pišu radove o tvom blogu", rekao je. "Ne kažem da treba da imaš akademski pristup niti da budeš dosadna. Zadrži svoj stil, ali dodaj više dubine". (Adiči, 2014: 371)

On dalje nastavlja:

"Znaš, nije dovoljno samo pisati blog, treba i živeti u skladu sa svojim uverenjima. Taj blog je igra koju ne uzimaš zaista ozbiljno, kao da si izabrala neki zanimljivi izborni predmet, neki večernji kurs da upotpuniš obrazovanje." (Adiči, 2014:409)

Kao što blog u romanu Amerikana narušava klasičnu strukturu književnog dela, tako i necenzurisan jezik, ispovedna naracija kao kombinacija javnog i privatnog u formi bloga tj. građanskog novinarstva, postavlja nove norme teksta. Zaogrnuta plaštom anonimnosti, Ifemelu je u stanju da piše i o svojim ličnim problemima i nedoumicama, ali i da sa distance ukazuje na društvene nepravde sistema u kome se nalazi: "To može biti utopijska vizija pobornika blogosfere, tj. da taj medij služi kao oruđe za podstrekivanje demokratije, možda čak i neposredne demokratije" (Dejvis, 2009:37). Vremenom, blog u potpunosti zaokuplja Ifemelu, ona postaje blog - glasilo društvene nepravde. lako prema svom blogu oseća i naklonost i strah, čitaoci su ti prema kojima oseća strahopoštovanje i obavezu: “Uvek su je plašili i oduševljavali svi ti čitaoci, čiji je broj rastao iz meseca u mesec i koji su se povezivali i unakrsno komentarisali, koji znaju mnogo više od nje" (Adiči, 2014:11). 
"U 21. veku bloga, Tvitera i društvenih mreža, mi već živimo u globalnom onlajn selu, grupišući se po mišljenju, životnom stilu i ideologiji" (Kros, 2011:1). Međutim, Krosova dalje navodi: “Okružujući sebe ljudima koji misle kao i ti možda deluje udobno, ali može izroditi netoleranciju i ekstremizam" (Kros, 2011:13). Sa popularnošću bloga raste i popularnost Ifemelu. Potvrda uspešnosti dolazi u vidu novčane satisfakcije i poziva da drži predavanja u kolektivima o rasizmu i međurasnoj toleranciji. Otkrovenje, pak, dolazi u vidu imejla koji dobija nakon radionice o različitosti: "PREDAVANJE TI JE BILO KOJEŠTARIJA. TI SI RASISTA. TREBA DA BUDEŠ ZAHVALNA ŠTO SU TE PUSTILI U OVU ZEMLJU” (Adiči, 2014: 362). Ifemelu shvata da pozivi znače da je potrebno samo njeno puko prisustvo, da niko ne želi da čuje pravu istinu već da polaznici treba dobro da se osećaju nakon predavanja. Uljuljkana popularnošću svog bloga među istomišljenicima, Ifemelu shvata da je surova realnost o kojoj piše na svom blogu istina koja je okružuje, ali koja se može izgovoriti samo u virtuelnom svetu.

Poučena iskustvom, Ifemelu na predavanjima počinje da govori ono što ljudi žele da čuju, a na blogu piše o stvarima kakve zaista jesu. Ali, kome se ona zapravo obraća svojim blogom? "Većina blogera su uglavnom belci" (Bolander, 2013:39), to su većinom Amerikanci (29.2\%), iako skoro 28\% stanovništva Amerike, iz različitih razloga, nema pristup internetu (Kros, 2011). Pisanje bloga je "znak emancipacije", jer prosečan, marginalizovan, "mali" čovek dobija priliku da izrazi javno svoje stavove (Dejvis, 2009:6). Međutim, kako je rasa usko povezana sa klasom u Americi, da se zaključiti da Ifemelin blog o rasnim pitanjima ne čitaju ljudi koji trpe najveće ugnjetavanje. I pisci i čitaoci blogova su uglavnom mladi obrazovani ljudi, uz pristup internetu pretpostavlja se da su i ekonomski situirani. lako "ljudi svih rasa mogu imati predrasude ili se preterano ponositi rasom, odnosi se na individualni ili individualizovani rasizam, i ovo opisuje pojedince koji svesno ili nesvesno favorizuju jednu rasu u odnosu na drugu" (Barak i dr., 2010:100), popularno je mišljenje da belci smatraju da nemaju rasu, a diskriminisane manjine nemaju moć diskriminacije nad belom većinom. Stoga, Ifemelin blog u Amerikani ne poziva čitaoce na akciju, već ih samo podseća na realnost. Ponovo se nameće pitanje opasnosti "jedne priče": "Moć je sposobnost ne samo da se ispriča priča o drugoj osobi, već 
da se učini da to bude konačna priča te osobe" (Adiči, 2009). ${ }^{9}$ Realnost u Americi je da je bela većina odredila konačnu priču o crnoj manjini.

lako blog u romanu Amerikana ne daje rešenja za postojeće probleme, on osvetljava i stavlja pod lupu pitanja o kojima se retko govori. Od upoznavanja sa rasom i svim nijansama boje kože od bele do crne, do političke korektnosti i anagažovanosti (predsednička izborna kampanja Baraka Obame), nerealnih slika lepote koju plasiraju modni magazini ignorišući crne žene i čuvenog pitanja prirodne, kovrdžave kose crnkinja (metafore za rasu). Svi ovi problemi, bez obzira koliko se činili veliki ili mali, postoje i njihovo ignorisanje neće doprineti njihovom nestajanju. Ifemelin blog ukazuje na to koliko je "obećana zemlja" u stvari obećana privilegovanoj, beloj većini, i da ekonomski i politički jaka i tehnološki napredna država kao što je Amerika tek treba da se uhvati u koštac sa rasnim i klasnim društvenim podelama koje, uostalom, i sama podstiče.

Po povratku u Nigeriju, Ifemelu nastavlja sa pisanjem blogova. Zatvorivši blog u Americi, a samim tim i jednu životnu priču, Ifemelu otvara novi blog: Mala iskupljenja Lagosa. Glavna ideja je da piše o svom povratničkom životu i problemima sa kojima se susreće u Nigeriji. Dok su je raniji plašile horde čitalaca, Ifemelu se sada nalazi na "svom terenu" i smatra da ona zna više od svojih čitalaca i da joj to daje pravo da iznosi probleme koji su deo svakodnevnog života u Nigeriji. Ovoga puta, anonimnost nije dovoljna da stvori otklon i doprinese objektivnosti. Za razliku od SAD ne postoji distanca, pisanje je mnogo emotivnije i ličnije, rečnik nije "sirov" i grub, više piše o stvarnim događajima i ljudima, a razlika između blogera i stvarne osobe je mala. Dok je u SAD-u Ifemelu težila da bude nemi posmatrač društvenih nepravdi (kao migrant koji nema ni pravo ni moć da rešava probleme države koja nije njena), u Nigeriji njeni postovi su morališući i nude rešenja za probleme o kojima piše. Bolander kaže:

Blogeri ličnih dnevnika moraju da nađu ravnotežu između deljenja ličnih informacija i zaštite identiteta trećeg lica, na primer, članova porodice i prijatelja. Deljenje ličnih informacija je suštinski povezano sa oblikom bloga - ličnog dnevnika, i čitaoci očekuju da takve informacije nađu u postovima. (Bolander, 2013:30)

Ifemelu shvata da je prešla granicu i da se nije uspešno distancirala kada objavi post u kome detaljno opiše život svoje drugarice, devojke

Id. 
koja je skrenula sa "pravog puta" i živi život izdržavane ljubavnice. Intimne ispovesti u nigerijskom blogu moraju biti manje lične, jer u Nigeriji, za razliku od SAD, ljudi su prisniji, povezani i više vole da otkriju dobar trač no da razmišljaju o društvenim problemima. Takođe, ličniji odnos u pisanju bloga je očigledan i za vreme svađe Ifemelu i Obinze, gde ona svaki svoj post piše sa nadom da će ga Obinze pročitati i odobriti.

Mala iskupljenja Lagosa su dosta emotivniji blog, ali i dosta slabiji u kritici društva od onog koji je Ifemeliu pisala u Americi. Pojedini postovi kritikuju povratnike iz Amerike i Britanije, ali ništa ne piše o situaciji koja je naterala te ljude da napuste Nigeriju. Ifemelu kritikuje žene koje su izdržavane ljubavnice, ali ništa ne govori o tim muškarcima - mecenama (teta-Udžin General, čak i Obinzeov šef). Shvatamo da je za Ifemelu lakše da iznosi stavove o problemima države koja nije njena domovina, nego što je to moguće u rodnoj Nigeriji.

Adičijeva ne završava blogovsku kampanju sa završetkom romana Amerikana. Blog Mala iskupljenja Lagosa nastavlja da živi, a sa njim i Ifemelu i Obinze, kao i kritika društvenih problema u Nigeriji. ${ }^{10} \mathrm{Ka}$ što je već pomenuto, Ifemelu tj. Adičijeva ne samo da ukazuje na probleme, već i daje moguća rešenja (npr. problem ebole u Nigeriji, nedostatak osnovnog znanja i higijenske kulture i sl.). Još jednom, Adičijeva dokazuje da je svesna uticaja koji imaju digitalne forme i koristi ih, ne samo za promociju romana Amerikana, već i za razbijanje "jedne priče", čija god ona bila. Gvaracino navodi da: "Priče putuju ne samo kroz tradicionalni medij romana i kreativne fikcije, već i kroz rasprostranjeniju mrežu. Adiči se na ovaj način može smatrati delom široke društvene mreže koja artikuliše kontinuirani protok oblikovanja i preoblikovanja društvene svesti koji uključuje skup svih učesnika" (Gvaracino, 2014:9).

Razlažući tradicionalnu formu romana modernom tekstualnom formom bloga, Adičijeva je stvorila novu platformu ne samo za prenošenje priče, već i za kritikovanje postojećih društvenih problema i podizanje svesti po pitanju rasnih i klasnih pitanja. Dva bloga: Rejstint ili Razna zapažanja neameričke crnkinje o američkim crncima (nekada poznatim kao crnje) i Mala iskupljenja Lagosa opisuju lična iskustva iz života u SAD i Nigeriji. Blog koji Ifemelu piše u Americi je dosta distanciran (iako koristi svoja i iskustva bližnjih kao osnovu za svoje postove) i predstavlja kritiku društva koje se raslojava po rasnom i klasnom osnovu. Blogerka je posmatrač tih pojava i podiže svest o problemima, ali aktivno ne učestvuje u njihovom rešavanju.

Više na: http://americanahblog.com/ 
U Nigeriji blog je emotivniji, ličniji, ukazuje na probleme ali sada manje kritički. Mala iskupljenja Lagosa su pisana iz vizure starosedeoca koji ne može da se distancira onoliko koliko je to moguće u tuđoj zemlji.

Oba bloga su izuzetno značajna zato što ukazuju na probleme i nerazumevanja koja su integralni deo svakodnevnog života. Akcenat je stavljen na problem rase $u$ Americi (jer to je mesto gde Afrikanci postaju svesni rase i značaja crne boje kože), ali i na sve one ostale probleme koji proizilaze iz te rasne uslovljenosti. Zbog komentara čitalaca svaki blog je tekst u nastajanju, ali u Amerikani mi se ne upoznajemo sa tim nadograđenim delovima tekstova. Bilo bi zanimljivije videti koliki uticaj su imali postovi na publiku i da li su oni bili pokretači koji nagnaju čitaoce na promenu, ili samo tekstovi koji podižu svest o postojećem stanju stvari. U svakom slučaju odlomci iz postova su vredni samim tim što ukazuju na društvene probleme koristeći prijemčiv, neakademski jezik i što putem digitalnih medija mogu dopreti do velikog broja čitalaca.

\section{Literatura}

Adiči, Č.N. (2014). Amerikana. Beograd: Laguna.

Barak, G. et al. (2010). Class, Race, Gender, and Crime - The social Realities of Justice in America (3 ${ }^{\text {rd }}$ edition). Lanham - Boulder - New York - Toronto - Plymouth, Uk: Rowman \& Littlefield Publishers, Inc.

Berry, D.M. (ed.). (2012). Understanding Digital Humanities. Palgrave MacMilan.

Bolander, B. (2013). Language and Power in Blogs - Interaction, Disagreements and Agreements. Amsterdam/Philadelphia: John Benjamins Publishing Company.

Cross, M. (2011). Bloggerati, Twitterati - How Blogs and Twitter Are Transforming Popular Culture. Santa Barbara, California - Denver, Colorado - Oxford, England: PRAEGER.

Davis, R. (2009). Typing Politics - The Role of Blogs in American Politics. New York: Oxford University Press.

Gold, M.K. (ed.). (2012). Debates in The Digital Humanities. Minneapolis and London: University of Minesota Press.

Guarracino, S. (2014). "Writing <<so raw and true >>. Blogging in Chimamanda Ngozi Adichie's Americanah". Technologia; Immaginazione e forme del narrare. Ed. L. Esposito, E. Piga, A. Ruggiero. Between, IV.8. www.betweenjournal.it.

Schrebman, S. et al. (ed.) (2008). A Companion to Digital Humanities. Blackwell Publishing.

Internet izvori: 
Adichie, C.N. (2009). "The danger of a single story". Dostupno na: http://www. ted.com/talks/chimamanda_adichie_the_danger_of_a_single_story/ transcript?language=en. Pristup ostvaren: 04.08.2015.

Norris, M. (2014). "An Interview with "Americanah" Author Chimamanda Ngozi Adichie". Dostupno na: https://www.youtube.com/watch?v=2ijEqposkyk. Pristup ostvaren: 03.08.2015.

https://www.facebook.com/chimamandaadichie Pristup ostvaren: 04.08.2015.

http://americanahblog.com/ Pristup ostvaren: 04.08.2015.

http://www.azlyrics.com/lyrics/beyonceknowles/flawless.html Pristup ostvaren: 04.08.2015. 


\title{
Kristina Vištica
}

\section{DIGITAL HUMANISM AGAINST RACISM - THE ROLE OF BLOG IN AMERICANAH}

\begin{abstract}
Summary
Digital humanism, with its various definitions, could also be defined as the influence of digital on humanistic and the analysis of their intersection. Often criticized as the tool for creating the digital gap (economic, class, racial etc.), numerous projects (e.g. Google Books) have preserved from oblivion and destruction thousands of books and encouraged the so-called "distance reading", and modern textual forms (e.g. Twitter, blogs etc.) have changed the perception of literature, and become the instrument of resistance and reforms. The feminist writer Chimamanda Ngozi Adichie shapes the structure of her novel Americanah through excerpts of texts written by the novel's heroine Ifemelu. These blog excerpts summarize the topics of racism in America, and through the personal experience of the Nigerian girl - Ifemelu, Adichie gives examples of how racial issues permeate everyday life. Using this modern digital form within a classical structure of a novel, Adichie shows the link between the traditional and modern, infrangible nowadays. Analyzing the novel we see the difference between blogs written in America nad Nigeria. The American blog is more distant and objective in pinpointing the social flaws and racial and class issues in America. The Nigerian blog is more emotional and personal, and less critical than the American one. Both emphasize the social problems in both America and Nigeria, but the blogger seem to be a mere observer not the initiator of actions aimed to change the flaws. Even though the blog excerpts redesign the traditional form of a novel, they form a modern interwined text (always in the process of making with all the readers adding their comments) with the purpose of revealing the problems in social structures of the modern world.
\end{abstract}

Key words: Americanah, blog, digital, racism, traditional. 